\title{
Changes in Interleukin-6 Concentration in Peripheral Blood of Pre- and Post-Partum Dairy Cattle and Its Relationship to Postpartum Reproductive Diseases
}

\author{
Yukikazu ISHIKAWA $^{1)}$, Ken NAKADA ${ }^{1) *}$, Katsuro HAGIWARA ${ }^{2)}$, Rikio KIRISAWA ${ }^{2)}$, Hiroshi IWAI ${ }^{2)}$, \\ Masaharu MORIYOSHI ${ }^{1)}$ and Yutaka SAWAMUKAI ${ }^{1)}$ \\ ${ }^{1)}$ Departments of Large Animal Clinical Sciences and ${ }^{2)}$ Veterinary Microbiology, Graduate School of Veterinary Medicine, Rakuno \\ Gakuen University, Ebetsu, Hokkaido 069-8501, Japan
}

(Received 12 February 2004/Accepted 15 July 2004)

ABSTRACT. Reproductive diseases after parturition are a serious problem in dairy cattle. It is important to predict postpartum reproducti ve diseases early and to develop prophylaxis. The objectives of this study were to demonstrate changes in the peripheral blood con centration of interleukin-6 (IL-6) before parturition, which was mainly produced by T helper 2 type (Th2) cells, and to investigate a correlation between the IL- 6 concentration and the occurrence of the postpartum retained placenta, endometritis and/or follicular cyst in da iry cattle. Twenty-seven Holstein-Friesian cows were used for this study. Thirteen had no clinical disease, 8 had retained placenta, 4 were diagnosed with endometritis by vaginal inspection, and 2 were diagnosed with follicular cyst by rectal palpation at 1 and 2 months a fter parturition. Blood samples were collected 60 days pre- and post-partum. They used for IL-6, progesterone $\left(\mathrm{P}_{4}\right)$ and estradiol-17 $\beta\left(\mathrm{E}_{2}\right)$ concentration determination. This study showed that the IL-6 concentration prepartum was higher than postpartum. Low levels of IL6 and $\mathrm{P}_{4}$ in peripheral blood prepartum tended to affect retained placenta and a high level of IL- 6 prepartum tended to affect endometrit is. These results indicate that measurement of change in the IL- 6 concentration during pregnancy is one useful tool for predicting crisis in postpartum reproductive diseases in dairy cattle.

KEY WORDS: cattle, endometritis, interleukin-6, pregnant, retained placenta.

J. Vet. Med. Sci. 66(11): 1403-1408, 2004

Reproductive diseases after parturition are a serious problem in dairy cattle. These diseases delay recovery of ovarian function and uterus involution postpartum, and accordingly extend the time from parturition to conception. Therefore, not only do these diseases lower productivity and fertility, and but they also bring economic loss to the dairy farm. It is important to predict postpartum reproductive diseases as early as possible, and to develop a prophylaxis to prevent these diseases.

Main postpartum reproductive diseases in dairy cattle are retained placenta, endometritis and follicular cyst. Retained placenta occurred in postpartum cows at a rate of 4-12\% [2, $3]$, in which the fetal placenta was not expelled from the uterus until $12 \mathrm{hr}$ after parturition [20]. Many cattle that had retained placenta successively had endometritis or pyometra, and their parturition interval was extended, so that uterine involution was delayed. As for the cause of retained placenta, it was considered to be due to anatomy, heredity, nutrients and/or a deficiency of the blood progesterone concentration during pregnancy [1] but it was difficult to determine the exact cause. Endometritis was observed in many postpartum cattle within 14 days after parturition. Cattle with endometritis at more than 14 days after parturition had a high risk of infertility and/or sterility [10]. Follicular cyst was the disease in which ovarian follicles larger than $2.5 \mathrm{~cm}$ are present in the ovary, and was not observed at ovulation. Many cattle had cystic follicular structure observed from

\footnotetext{
* Correspondence to: Nakada, K., Department of Large Animal Clinical Sciences, Graduate School of Veterinary Medicine, Rakuno Gakuen University, Ebetsu, Hokkaido 069-8501, Japan.
}

15-45 days after parturition, and follicular cysts as a reproductive disease were mainly diagnosed at 1 to 4 months after parturition. As for the cause of follicular cysts, it was considered that the hypothalamus and pituitary gland were not able to respond to high concentrations of blood estradiol$17 \beta\left(\mathrm{E}_{2}\right)$ for induction of estrous events including preovulatory GnRH-LH surge secretion [16, 22]. It was thought that a factors in the induction of these reproductive disorders are to feed a large amount of concentrate for milk production and/or much stress applied to the body by milking, housing and feeding systems in high yield dairy cattle [4, 8, 22]. Therefore, from new viewpoints, it is necessary to establish inspection guidelines that are aimed at the disclosure and elimination of risk factors for postpartum reproductive diseases during pregnancy as early as possible. These must be connected to provide a method of early diagnosis and prophylaxis for these reproductive diseases.

It has been reported that cytokine and growth factors with reproductive hormones may locally or systemically play important roles in placental development and prevention of fetal loss during pregnancy, for elimination of the fetus and fetal membrane at parturition, and for the phylaxis postpartum in humans and rodents $[17,21,27,28]$. Local immune cells or cytokines in the uterus played roles in maintaining pregnancy, support fetal growth and preventing infection [19]. The authors think that it is especially important for elimination of the fetal membrane and phylaxis after parturition to shift from T-helper 2-type (Th2) cell dominance to T-helper 1-type (Th1) cell dominance of T-helper cells in the intrauterine immune system around parturition. We then hypothesized that if the local/systemic immune function 
could be monitored during pregnancy and the mechanism leading from a prepartum immune functional deficiency to the occurrence of a crisis in postpartum reproductive diseases could be clarified, then an improved method of diagnosis and a better approach to prevention of postpartum reproductive diseases in dairy cattle might be devised.

The objective of this study was to clarify the change in the peripheral blood concentration of interleukin-6 (IL-6), which is mainly secreted by Th2 cells, and to investigate the relationships among changes in IL- $6, \mathrm{P}_{4}$ and $\mathrm{E}_{2}$ concentrations before parturition. Furthermore, this study was also carried out to analyze whether there were some links between these hormonal changes before parturition and reproductive diseases postpartum or not.

\section{MATERIALS AND METHODS}

Animals: A total of 27 Holstein-Friesian cows that were fed on Rakuno Gakuen University Farm were used for the study. The average parity times of the animals were $2.5 \pm$ 0.4 . Eight cows had a retained placenta where the fetus placenta was not drained from the uterus $12 \mathrm{hr}$ after delivery. Four cows were diagnosed with endometritis by vaginal inspection at the medical flesh examination 22 to 35 days after parturition. And two cows also were diagnosed with ovarian follicular cyst by rectal palpation at the same time. The other 13 cows did not have any clinical diseases during the experiment.

Collecting samples: Blood samples were collected by tail vein puncture at $60,30,21,14,9,7,5,4,3,2$ and 1 day before the estimated day of parturition, and every two days until 60 days after parturition. Blood samples for serum were stored at $4^{\circ} \mathrm{C}$ for $6-10 \mathrm{hr}$ and were then centrifuged at $1,700 \times \mathrm{g}$ for $20 \mathrm{~min}$. These sera were decanted and stored at $-30^{\circ} \mathrm{C}$ until the concentration of IL- 6 was determined. Heparinized blood samples for plasma were immediately centrifuged at $1,700 \times \mathrm{g}$ for $20 \mathrm{~min}$. They were also stored at $-30^{\circ} \mathrm{C}$ until the $\mathrm{P}_{4}$ and $\mathrm{E}_{2}$ concentrations were determined.

Determination of IL-6: The serum IL-6 concentration was determined by Time-resolved immunofluorometric assay (Tr-FIA) which we modified with a sandwich ELISA as previously described by Hagiwara et al. [6] and used Europium (Eu)-labelled streptavidin (Wallac, Finland) instead of horseradish peroxidase (HRP)-labelled streptavidin. Briefly, we have shown this assay protocol in Fig. 1. Affinity purified anti-bovine IL-6 rabbit IgG was coated on assay plates and incubated for $12 \mathrm{hr}$ at $25^{\circ} \mathrm{C}$. Recombinant bovine IL-6 as the standard was diluted from $78-20,000 \mathrm{pg} / \mathrm{ml}$ in twice serial dilution. The serum samples were diluted twice. Fifty $\mu l$ of them was added to each well in the assay plate and incubated for $10 \mathrm{hr}$ at $25^{\circ} \mathrm{C}$. After washing the plate, 50 $\mu l$ of biotin conjugated affinity purified anti-bovine IL-6 rabbit IgG was added to each well of the assay plate and incubated for $12 \mathrm{hr}$ at $25^{\circ} \mathrm{C}$. After washing the plate, $50 \mu \mathrm{l}$ Eu-labelled streptavidin was added to each well of the assay plate, and incubated for $1 \mathrm{hr}$ at $25^{\circ} \mathrm{C}$. After washing the plate, $50 \mu l$ of enhancement solution (Wallac, Finland) was added, and measured on a Wallac 1420 ARVOsx multilabel counter (Wallac, Finland). The sensitivity of the assay for IL-6 was $0.2 \mathrm{ng} / \mathrm{ml}$ and the intra- and inter- assay coefficients of variation were 9.1 and $21.3 \%$ respectively.

Determination of $E_{2}$ concentration: The plasma $\mathrm{E}_{2}$ concentration was determined by double antibody radio immunoassay (RIA) after extraction with diethyl ether as described by Taya et al. [25]. The RIA used antisera of estradiol - $17 \beta$ (GDN\# 244 [9]) that was given by Dr. G.D.Niswender of America Colorado state University, and ${ }^{125}$ I -labeled estradiol (Amersham, cord IM - 135). The sensitivity of the assay for $\mathrm{E}_{2}$ was $0.16 \mathrm{pg} / \mathrm{ml}$, and the intra- and inter- assay coefficients of variation were 6.7 and $17.8 \%$ respectively.

Determination of $P_{4}$ concentration: The plasma $\mathrm{P}_{4}$ concentration was determined by double antibody enzyme immunoassay (EIA) after extraction with diethyl ether as described by Prakash et al. [15]. The EIA used antibodies of rabbit anti progesterone - 3 - CMO - BSA (Biogenesis, Poole, U.K.), and horseradish peroxidases labeled progesterone. The sensitivity of the assay $\mathrm{P}_{4}$ was $10 \mathrm{pg} / \mathrm{ml}$, and the intra- and inter- assay coefficients of variation were 9.8 and $8.3 \%$ respectively.

Statistical analysis: Results were subjected to an analysis of variance for repeated measures. When a significant effect was obtained with an analysis of variance. All data were

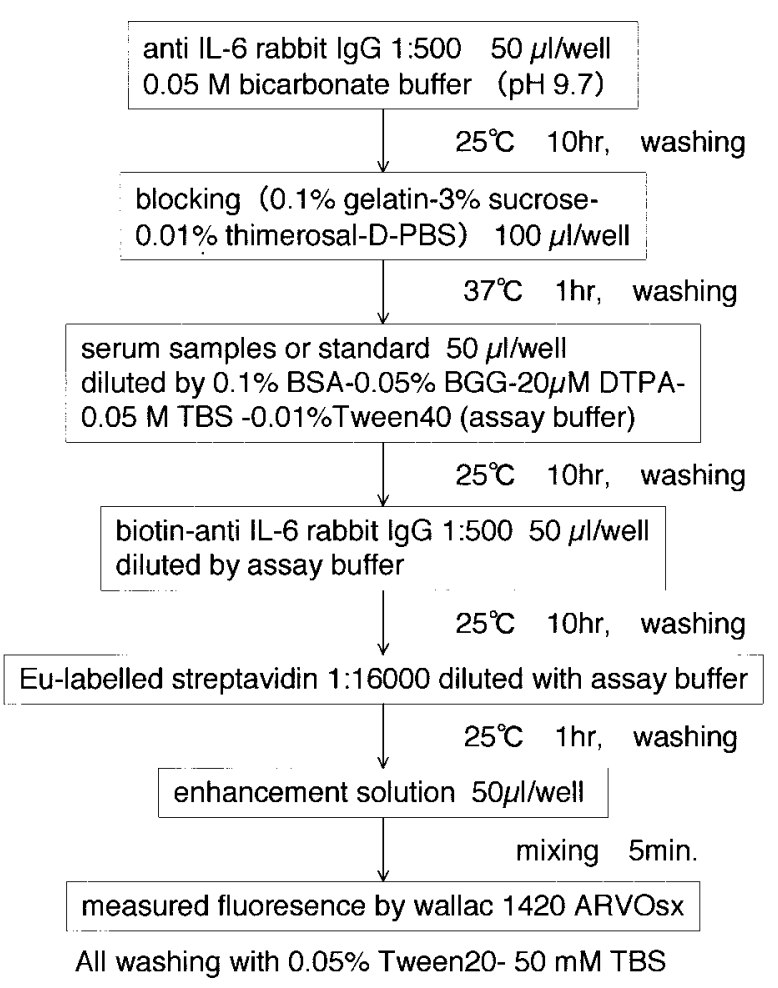

Fig.1. Time-resolved immunofluorometric assay protocol of serum IL-6 in cows. 

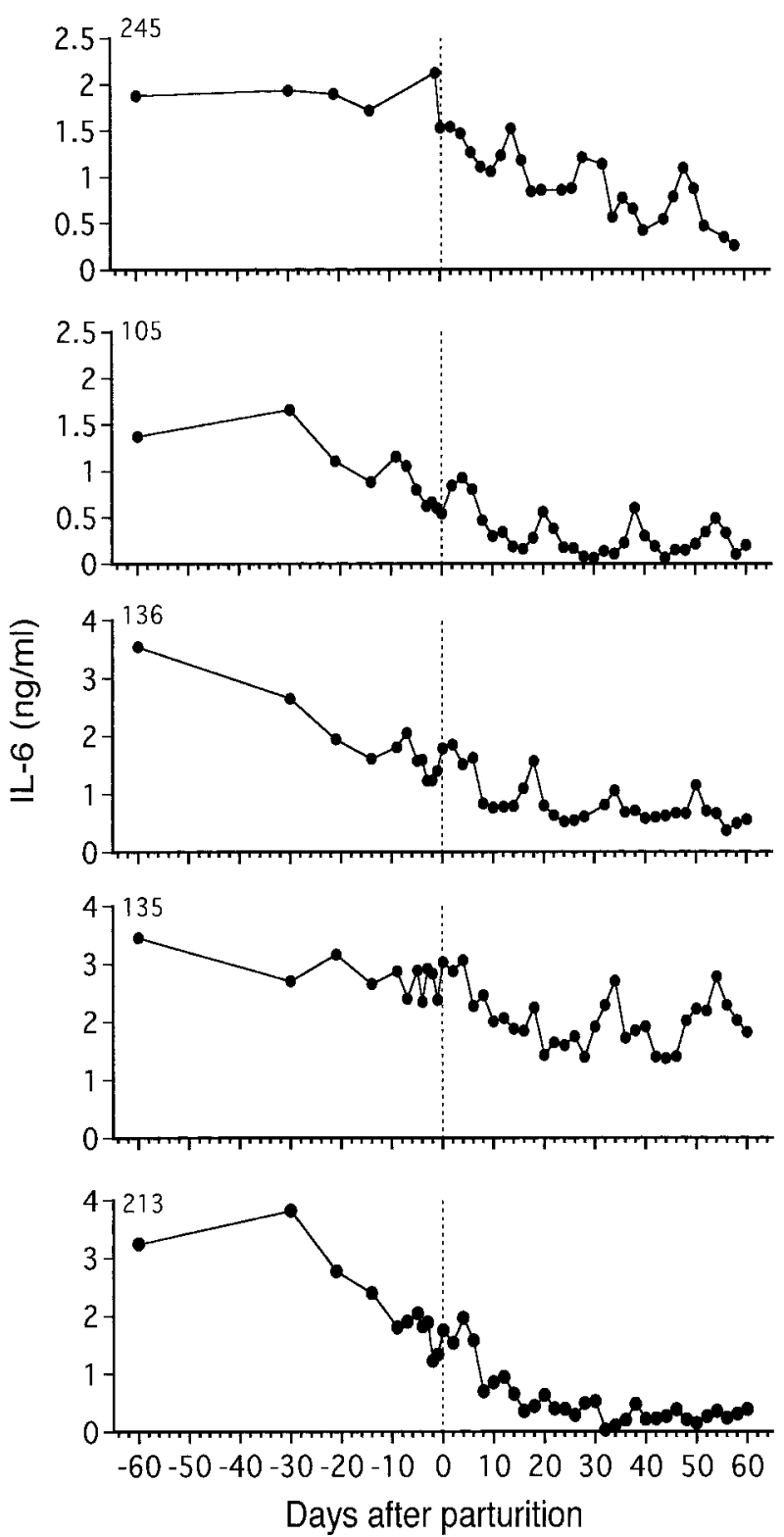

Fig.2. Individual changes in IL-6 concentration of peripheral blood for 60 days pre- and post-partum in 5 normal cows.

analyzed with the Excel Statistical Analysis System. A value of $p<0.05$ was considered to be significant.

\section{RESULTS}

Five individual typical changes in the peripheral IL-6 concentration in dairy cows, that were not affected by postpartum reproductive diseases, are shown in Fig. 2. The IL6 concentration was recognized at a difference in the range $1.4-3.5 \mathrm{ng} / \mathrm{ml}$ between animals 60 days before parturition. It gradually decreased until the parturition day. The IL-6 concentrations before parturition had a tendency to be higher than those after parturition. This tendency was observed in all normal cows.

Changes in IL-6, $\mathrm{P}_{4}$ and $\mathrm{E}_{2}$ concentrations for 60 days before and after parturition are shown in Fig. 3. Before parturition, The IL- 6 concentrations changed in the range $2.1 \pm$ $0.5-2.7 \pm 0.4 \mathrm{ng} / \mathrm{ml}$. The IL-6 concentrations before parturition were significantly higher than those after parturition $(\mathrm{p}<0.05)$. The $\mathrm{P}_{4}$ concentration gradually decreased from 60 days $(4.2 \pm 0.2 \mathrm{ng} / \mathrm{ml})$ to 5 days $(2.0 \pm 0.2 \mathrm{ng} / \mathrm{ml})$ before parturition, then it rapidly decreased from 3 days $(1.6 \pm 0.1 \mathrm{ng} /$ $\mathrm{ml}$ ) before parturition to parturition day $(0.11 \pm 0.01 \mathrm{ng} / \mathrm{ml})$. The $E_{2}$ concentration from 60 to 21 days before parturition remained between $30.0 \pm 3.6$ and $37.7 \pm 3.6 \mathrm{pg} / \mathrm{ml}$, then it rapidly increased and reached a peak of $539.6 \pm 70.2 \mathrm{pg} / \mathrm{m} l$ at 3 days before parturition. The $\mathrm{E}_{2}$ concentration changed in the range of $3.9 \pm 0.4-8.0 \pm 1.4 \mathrm{pg} / \mathrm{m} l$ for 60 days after parturition.

Changes in The IL- 6 concentration in cows, that had postpartum reproductive diseases, are shown in Fig. 4. Twentyseven animals were divided into 4 groups according to reproductive diseases. Thirteen animals were a normal group, which did not have a retained placenta, emdometritis, follicular cyst or other diseases after parturition. Eight were a retained placenta group, 4 were endmetritis group and 2 were a follicular cyst group. IL- 6 concentrations before parturition in the endmetritis group were higher than those in the normal group $(\mathrm{p}<0.05)$, whereas IL-6 concentrations before parturition in the retained placenta group were lower than those in the normal group $(\mathrm{p}<0.05)$. Change in IL-6 concentrations in the follicular cyst group were similar to those in the normal group.

Changes in the $\mathrm{P}_{4}$ concentration in cows that had postpartum reproductive diseases are shown in Fig. 5. There was the tendency for the progesterone concentration changed generally low in retained placenta group as compared with that in the normal group. In the endmetritis and follicular cyst groups, the $\mathrm{P}_{4}$ concentrations before parturition were similar to those in the normal group, and a fixed tendency was not observed. No difference was not observed in the prepatum $\mathrm{E}_{2}$ concentration among 4 groups.

\section{DISCUSSION}

This study showed that IL-6 concentrations before parturition were higher than those after parturition. IL-6 is known to be a cytokine produced by $\mathrm{T}$ cells. $\mathrm{T}$ cells are classified roughly into Th1 cells and Th2 cells by the method of cytokine production. The Th1 cell induces cell mediated immunity by producing mainly IL-2, TNF- $\alpha$, and IFN- $\gamma$, and the Th 2 cell induces antibody production by producing mainly IL-4, IL-5, IL-6, IL-10 and IL-13 [11]. Pregnancy had been thought to be an immuno-suppressed condition, but maternal lymphocytes were activated and clearly secreted most cytokines in the human deciduas. Saito et al. [18, 19] suggested that during pregnancy, Th1 cell function was restrained and it became clear that the Th2 
(a)

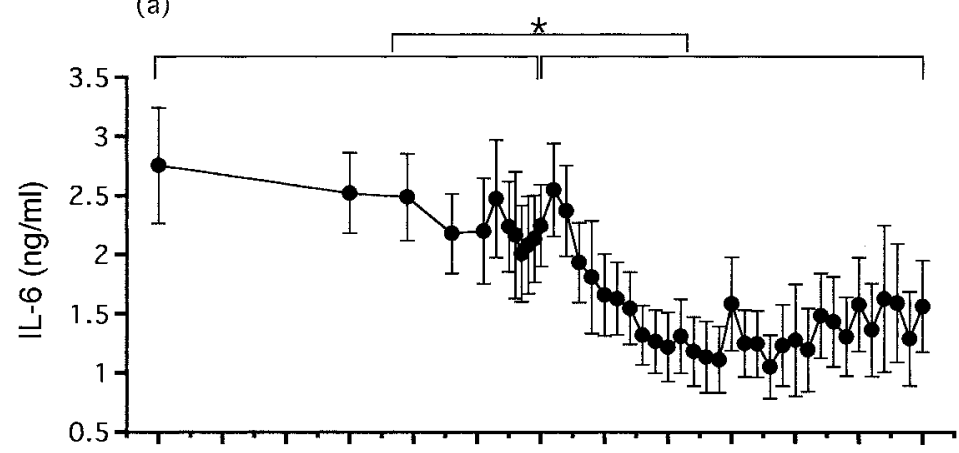

(b)

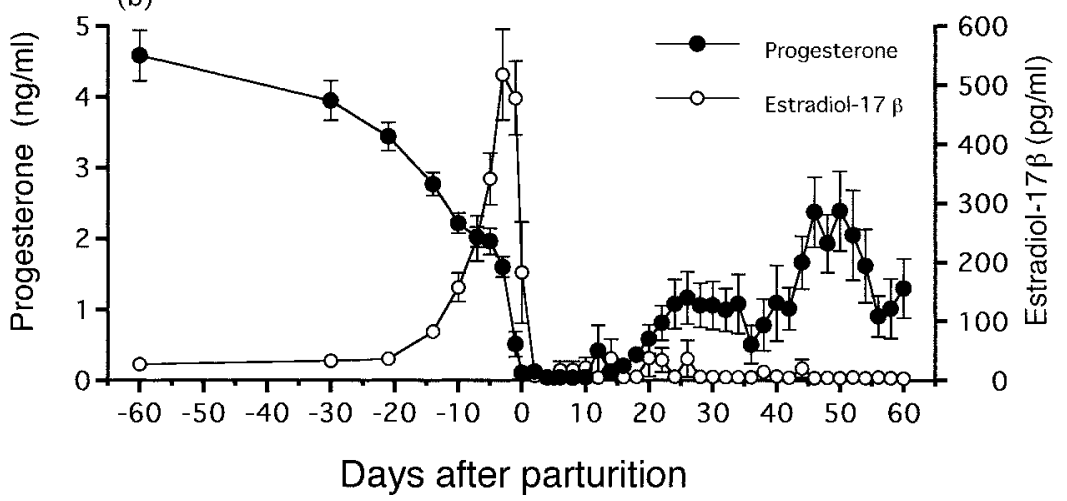

Fig.3. Changes in peripheral concentrations of IL-6, progesterone and estradiol-17 $\beta$ for 60 days pre- and postpartum in cows. Values are the mean \pm SEM $(n=27)$. IL- 6 concentrations prepartum were significantly higher than those postpartum $\left({ }^{*} \mathrm{p}<0.05\right)$ in the variance analysis.

cell function became dominant in mice and humans. IL-6 was identified in placenta, amnion, deciduas and myometrium [5]. Our results also suggested that immune function during pregnancy in cows was in an active state rather than restrained, and humoral immunity became dominant in pregnant cows. On the other hand, this study showed that the peripheral blood IL-6 level decreased until 8 days postpartum. This indicated that the recovery of the immune system from a pregnant immune system for keeping the conceptus was within one week postpartum. Monitoring of the peripheral IL- 6 concentration around parturition in cows has the possibility of objectively knowing the status of pregnancy and the maternal adaptability to pregnancy and parturition.

The $\mathrm{P}_{4}$ concentration gradually decreased for 60 days prepartum and suddenly diminished from 3 days before parturition to the parturition day. Between the parturition day and 24 days postpartum, it maintained a low level of less than 1 $n \mathrm{~g} / \mathrm{m} l$. In addition, the $\mathrm{E}_{2}$ concentration changed to a low level from 60 to 21 days before parturition and began to gradually rise afterward. It showed a sudden increase at 10 days pre-partum and maintained a high level until parturition. These results agreed with a previous report by Smith et al. [23] that the $\mathrm{P}_{4}$ concentration which showed a decline from 2 days pre-partum to the day before parturition, and the E2 concentration showed a peak on parturition day. In addi- tion, from 60 to 9 days before parturition the $E_{2}$ level increased with a decline in the $\mathrm{P}_{4}$ level. These results are similar to what was reported by Thorburn et al. [26].

In this experimental period, 8 cows were diagnosed with retained placenta, 4 cows with endometritis and 2 cows with ovarian follicular cysts. All IL- 6 and a part of $\mathrm{P}_{4}$ levels before parturition were low in retained placenta group as compared with those in normal group. $\mathrm{P}_{4}$ played very important roles in inducing implantation on the endometrium, to restrain the uterus muscular contraction and to make a suitable environment for pregnancy maintenance [12]. In addition, $\mathrm{P}_{4}$ inhibited activity of the NK cell in the uterus, and induced conversion from a Th0 cell to a Th2 cell and the release of cytokines such as IL-6 and IL-4 in trophoblasts. In humans, IL-6 and IL-4 promoted hCG secretion, then hCG stimulated secretion of $\mathrm{P}_{4}$ in the corpus luteum $[13,14]$. In the retained placenta group, a low concentration of IL- 6 and $\mathrm{P}_{4}$ before parturition meant that there was some anomaly in placental function, and it was thought to contribute to a retained placenta. As a factor in placenta retention, Joosten et al. [7] reported that compatibility of a major histocompatibility complex (MHC) class I molecules participated. Half of the MHC were of paternal origins, and a fetus was an allograft to the mother. Therefore, the mother should refuse a fetus. Nevertheless the presence of a specific immunologic mechanism for pregnancy maintenance 


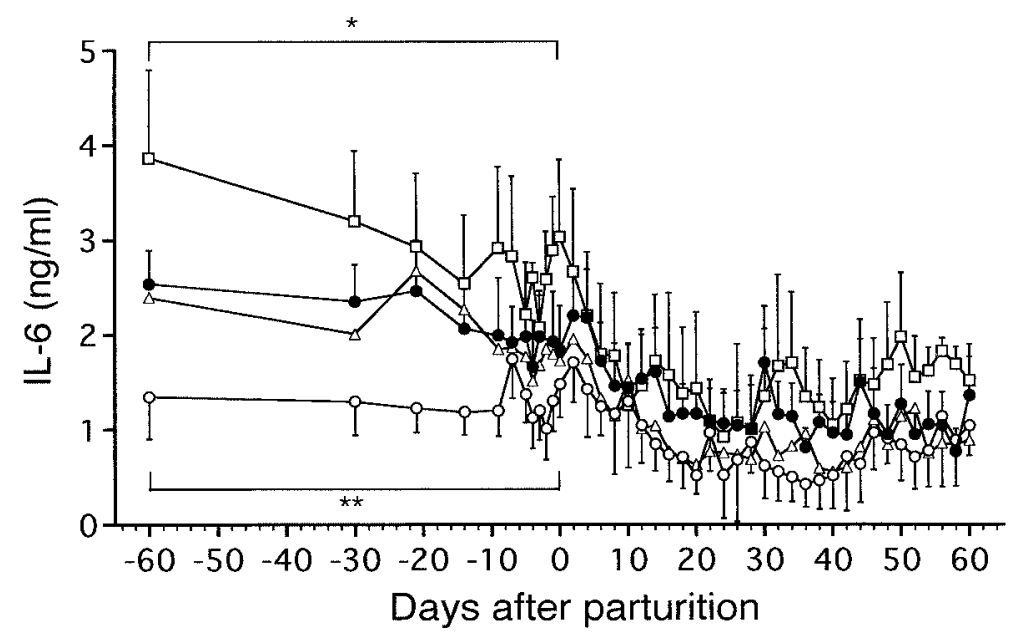

Fig.4. Changes in the serum IL-6 concentration for 60 days pre- and post-partum in normal $(\bigcirc, n=13)$, retained placenta $(O, n=8)$, endometritis $(\square, n=4)$, and ovarian follicular cysts $(\Delta, n=2)$ group. Values are the mean \pm SEM. IL-6 concentrations prepartum in the retained placenta and endometrits groups were significantly different from those in the normal group $(*, * * p<0.05)$ in the variance analysis.

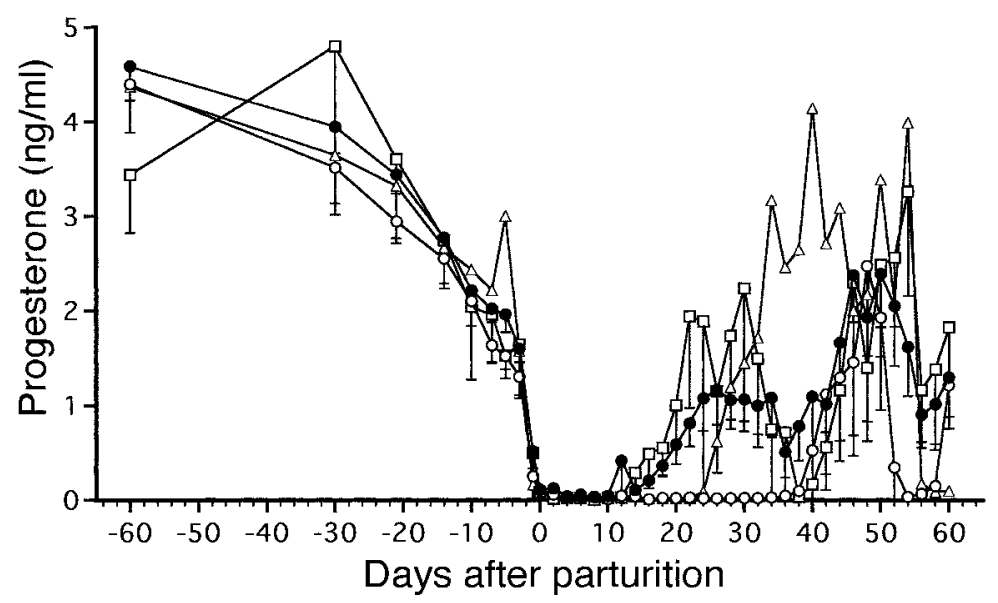

Fig.5. Changes in progesterone concentration for 60 days pre- and post-partum in the normal $(, n=13)$, retained placenta $\bigcirc(, n=8)$, endometritis $\square(, n=4)$, and ovarian follicular cysts $(\Delta, \mathrm{n}=2)$ groups. Values are the mean \pm SEM.

is suggested. In MHC class I molecular activity, it was thought that the fetal placenta produced an initial signal inducing pregnant maintenance immune reactions in human [24]. In cows, the appearance of a similar MHC class I molecule was confirmed [7]. It was thought that the pattern of expression with MHC class in placentation played an important role in whether the conceptus was refused by the mother as an allograft or not. Therefore, the incidence of a retained placenta points to a high affinity between the mother and fetus. The present results may indicate that the retained placenta group changes to a low level of IL-6 during the pregnancy and has a low reaction to the allograft. This suggested that the cause of retained placenta was abnormality of a shift in the immune system at delivery.
In contract to findings in the retained placenta group, in the endometritis group the IL- 6 levels tended to increase before parturition and the $\mathrm{P}_{4}$ concentrations reverted to levels exhibited in the normal group except for day 60 before parturition. This suggests that ideally, at parturition the transaction, or shift, from the Th2 immune system to the Th1 system should occur rapidly in the uterus, thus switching from the system ( $\mathrm{Th} 2)$ that provides tolerance for the conceptus to the immune system (Th1) that offers protection against infectant via the birth canal. From this study, the proposal can be made that inactivity of the immune mechanism causes endometritis. Given that the prepartum Il-6 concentration was high in cows that had endometritis after parturition, an abnormal placental function was suspected, 
and conversion of immune system at delivery was deemed insufficient.

The present study showed that the IL-6 concentration in the peripheral blood of pregnant dairy cows was measurable, and the value showed a change in various factors for postpartum reproductive diseases during pregnancy. Therefore, it is thought that immunization-related substances, including IL-6, are influenced in pregnancy maintenance and parturition with various hormones and other factors. Measurement of immunization-related substances for maintenance of pregnancy and parturition in pregnant cattle shows a possibility to predict a crisis of postpartum reproductive disorders before parturition. This study could show only a change in IL-6 as a dominant cytokine in Th2. Furthermore, analysis of many related factors in many directions will be necessary in order to increase the predictive accuracy of the crisis of postpartum reproductive diseases at an early pregnant stage in dairy cattle.

ACKNOWLEDGEMENTS. This work was supported by Grants-in-Aid for scientific research from the Japanese Ministry of Education, Culture, Sports, and Technology (No.15780203), and by Grants-in-Aid to Cooperative Research from Rakuno Gakuen University (Nos. 2002-4, 2003-7, 2004-8).

\section{REFERENCES}

1. Borsberry, S. and Dobson, H. 1989. Periparturient diseases and their effect on reproductive performance in five dairy herds. Vet. Rec. 124: 217-219.

2. Erb, H. N., Smith, R. D., Oltenacu, P. A., Guard, C. L., Hillman, R. B., Powers, P. A., Smith, M. C. and White, M. E. 1985. Path model of reproductive disorders and performance, milk fever, mastitis, milk yield, and culling in Holstein cows. $J$. Dairy Sci. 68: 3337-3349.

3. Esslemont, R. J. and Kossaibati, M. A. 1996. Incidence of production diseases and other health problems in a group of dairy herds in England. Vet. Rec. 139: 486-490.

4. Garverick, H. A. 1997. Ovarian follicular cysts in dairy cows. J. Dairy Sci. 80: 995-1004.

5. Gregory, E. R. 2001. Cytokaine and the Intation of parturition. pp. 113-146. In: The Endocrinology of Parturition (Smith.), KARGER, Switzerland.

6. Hagiwara, K., Kataoka, S., Yamanaka, H., Kirisawa, R. and Iwai, H. 2000. Detection of cytokines in bovine colostrum. Vet. Immunol. Immunopathol. 76: 183-190.

7. Joosten, I., Sanders, M. F. and Hensen, E. J. 1991. Involvement of major histocompatibility complex class I compatibility between dam and calf in the aetiology of bovine retained placenta. Anim. Genet. 22: 455-463.

8. Kawate, N., Yamada, H., Suga, T., Inaba, T. and Mori, J. 1997. Induction of luteinizing hormone surge by pulsatile administration of gonadotropin-releasing hormone analogue in cows with follicular cysts. J. Vet. Med. Sci. 59: 463-466.

9. Korenman, S. G., Stevens, R. H., Carpenter, L. A., Robb, M., Niswender, G. D. and Sherman, B. M. 1974. Estradiol radioimmunoassay without chromatography: procedure, validation and normal values. J. Clin. Endocrinol. Metab. 38: 718-720.

10. Lucy, M. C. 2001. Reproductive loss in high-producing dairy cattle: where will it end? J. Dairy Sci. 84: 1277-1293.

11. Mosmann, T. R., Cherwinski, H., Bond, M. W., Giedlin, M. A. and Coffman, R. L. 1986. Two types of murine helper T cell clone. I. Definition according to profiles of lymphokine activities and secreted proteins. J. Immunol. 136: 2348-2357.

12. Okuda, K., Uenoyama, Y., Naito, C., Sakabe, Y. and Kawate, N. 1999. Luteinizing hormone receptors in the bovine corpus luteum during the oestrous cycle and pregnancy. Reprod. Fertil. Dev. 11: 147-151.

13. Piccinni, M. P., Maggi, E. and Romagnani, S. 2000. Role of hormone-controlled T-cell cytokines in the maintenance of pregnancy. Biochem. Soc. Trans. 28: 212-215.

14. Piccinni, M. P., Scaletti, C., Maggi, E. and Romagnani, S. 2000. Role of hormone-controlled Th1- and Th2-type cytokines in successful pregnancy. J. Neuroimmunol. 109: 30-33.

15. Prakash, B. S., Meyer, H. H., Schallenberger, E. and van de Wiel, D. F. 1987. Development of a sensitive enzymeimmunoassay (EIA) for progesterone determination in unextracted bovine plasma using the second antibody technique. J. Steroid Biochem. 28: 623-627.

16. Ribadu, A. Y., Nakada, K., Tanaka, Y., Moriyoshi, M., Zhang, W. C. and Nakao, T. 1999. Lack of LH response to exogenous estradiol in heifers with ACTH-induced ovarian follicular cysts. J. Vet. Med. Sci. 61: 979-981.

17. Robertson, S. A., Seamark, R. F., Guilbert, L. J. and Wegmann, T. G. 1994. The role of cytokines in gestation. Crit. Rev. Immunol. 14: 239-292.

18. Saito, S., Sakai, M., Sasaki, Y., Tanebe, K., Tsuda, H. and Michimata, T. 1999. Quantitative analysis of peripheral blood Th0, Th1, Th2 and the Th1:Th2 cell ratio during normal human pregnancy and preeclampsia. Clin. Exp. Immunol. 117: 550555.

19. Saito, S., Tsukaguchi, N., Hasegawa, T., Michimata, T., Tsuda, H. and Narita, N. 1999. Distribution of Th1, Th2, and Th0 and the Th1/Th2 cell ratios in human peripheral and endometrial $\mathrm{T}$ cells. Am. J. Reprod. Immunol. 42: 240-245.

20. Sandals, W. C., Curtis, R. A., Cote, J. F. and Martin, S. W. 1979. The effect of retained placenta and metritis complex on reproductive performance in dairy cattle - a case control study. Can. Vet. J. 20: 131-135.

21. Schafer-Somi, S. 2003. Cytokines during early pregnancy of mammals: a review. Anim. Reprod. Sci. 75: 73-94.

22. Silvia, W. J., Hatler, T. B., Nugent, A. M., Laranja da Fonseca, L. F. and Garverick, H. A. 2002. Ovarian follicular cysts in dairy cows: an abnormality in folliculogenesis Ovarian follicular cysts in dairy cows. Domest. Anim. Endocrinol. 23: 167177.

23. Smith, V. G., Edgerton, L. A., Hafs, H. D. and Convey, E. M. 1973. Bovine serum estrogens, progestins and glucocorticoids during late pregnancy parturition and early lactation. J. Anim. Sci. 36: 391-396.

24. Szekeres-Bartho, J. 2002. Immunological relationship between the mother and the fetus. Int. Rev. Immunol. 21: 471-495.

25. Taya, K. W. G. and Sasamoto, S. 1985. Radioimmunoassay for progesterone, testosterone and estoradiol- 17 beta ${ }^{125}$ I-iodohistamine radioligands. J. Anim. Reprod. 31: 186-197.

26. Thorburn, G. D. 1992. The placenta, PGE2 and parturition. Early. Hum. Dev. 29: 63-73.

27. Vince, G. S. and Johnson, P. M. 1996. Is there a Th2 bias in human pregnancy? J. Reprod. Immunol. 32: 101-104.

28. Voisin, G. A. 1998. Immunology understood through pregnancy. Am. J. Reprod. Immunol. 40: 124-129. 